DOI: https://doi.org/10.47233/jteksis.v1i2.46

\title{
PENGARUH PEMAHAMAN PAJAK, PELAYANAN APARAT PAJAK, SANKSI PERPAJAKAN DAN PREFERENSI RISIKO PERPAJAKAN TERHADAP KEPATUHAN WAJIB PAJAK( STUDI KASUS UMKM TOKO ELEKTRONIK DI KECAMATAN SITIUNG DHARMASRAYA)
}

Desi Permata Sari ${ }^{1}$, Ramdani Bayu Putra ${ }^{2}$, Hasmaynelis Fitri ${ }^{3}$, Agung Ramadhanu ${ }^{4}$ and Fadila Cahyani Putri ${ }^{5}$

Fakultas Ekonomi dan Bisnis, Universitas Putra Indonesia YPTK

Email : desipermatasari735@gmail.com

Abstrak

Tujuan penelitian ini adalah untuk mengetahui sejauh mana pengaruh pemahaman pajak, pelayanan aparat pajak, sanksi perpajakan dan preferensi risiko perpajakan terhdap kepatuhan wajib pajak. Data yang digunakan adalah data primer berupa penyebaran koesioner pada UMKM Elektronik yang ada di Kecamatan Sitiung Dharmasraya pada tahun 2019. Metode analisis yang digunakan adalah metode analisis linear berganda.Hasil penelitian ini menunjukkan bahwa pemahaman perpajakan secara parsial berpengaruh signifikan terhadap kepatuhan wajib pajak. Sedangkan pelayanan aparat pajak secara parsial berpengaruh signifikan terhadap kepatuhan wajib pajak. Sedangkan sanksi perpajakan secara parsial berpengaruh positif dan tidak signifikan terhadap kepatuhan wajib pajak. Sedangkan preferensi risiko perpajakan secara parsial berpengaruh signifikan terhadap kepatuhan wajib pajak. Sedangkan pemahaman perpajakan, pelayanan aparat pajak, sanksi perpajakan, preferensi risiko perpajakan berpengaruh signifikan terhadap kepatuhan wajib pajak.

Kata Kunci : Kepatuhan Wajib Pajak, Pemahaman Perpajakan, Pelayanan Aparat Pajak, Sanksi Perpajakan, Preferensi Risiko, Tingkat Kesadaran.

\section{Pendahuluan}

Bagi negara-negara yang ada di dunia khususnya Indonesia, pajak merupakan unsur penting bahkan paling penting dalam rangka untuk menopang anggaraan penerimanaa negara. Oleh karenanya, pemerintah Indonesia begitu menaruh perhatian besar terhadap sektor pajak. Pajak berdasarkan UndangUndang Nomor 28 tahun 2007 pasal 1 ayat 1 adalah kontribusi wajib kepada negara yang terutang oleh orang pribadi atau badan yang bersifat memaksa berdasarkan undang-undang, dengan tidak mendapatkan imbalan secara langsung dan dipergunakan untuk kepentingan negara bagi sebesar-besarnya kemakmuran rakyat.Pajak juga merupakan ujung tombak pembangunan negara Indonesia karena sebagian besar APBN negara Indonesia berasal dari penerimaan pajak, dan diharapkan pemerintah memberikan perhatian khusus terhadap pajak itu sendiri. Besarnya wajib pajak juga mempengaruhi meningkatnya sumber penerimaan karena semakin banyak jumlah wajib pajak yang patuh maka semakin meningkat sumber penghasilan negara. Akan tetapi peran aktif dan kesadaran wajib pajak atas kepatuhannya terhadap perpajakan sangat dibutuhkan dalam hal ini.

Pada tahun 2014 nilai pertumbuhannya sebesar 6,4\% dan pada tahun 2015 mengalami penurunan pada pertumbuhan sebesar $3,4 \%$, pertumbuhannya turun cukup rendah $4,1 \%$, dan pada 2018 pada 2016 pertumbuhannya naik menjadi $11,9 \%$, pada 2017 pertumbuhannya naik cukup tinggi $12,1 \%$. Jadi setiap tahunnya mengalami kenaikan dan penurunan. Berikut tabel penerimaan pajak dari tahun 2016-2018:

Tabel 1.1 :

Penerimaan Pajak Tahun 2014 - 2018 :

\begin{tabular}{|c|c|c|c|}
\hline TAHUN & TARGET & TERALISASI & $\begin{array}{c}\text { RATA } \\
- \\
\text { RATA }\end{array}$ \\
\hline 2014 & $\begin{array}{c}\text { Rp. } \\
1.146 .900 .000\end{array}$ & $\begin{array}{c}\text { Rp. } \\
1.550 .490 .800\end{array}$ & $6,4 \%$ \\
\hline 2015 & $\begin{array}{c}\text { Rp. } \\
1.240 .400 .000\end{array}$ & $\begin{array}{c}\text { Rp. } \\
1.508 .020 .370\end{array}$ & $3,6 \%$ \\
\hline 2016 & $\begin{array}{c}\text { Rp. } \\
1.285 .000 .000\end{array}$ & $\begin{array}{c}\text { Rp. } \\
1.555 .934 .200\end{array}$ & $11,9 \%$ \\
\hline 2017 & $\begin{array}{c}\text { Rp. } \\
\text { 1.472.700.000 }\end{array}$ & $\begin{array}{c}\text { Rp. } \\
1.736 .060 .100\end{array}$ & $4,1 \%$ \\
\hline 2018 & $\begin{array}{c}\text { Rp. } \\
1.618 .100 .000\end{array}$ & $\begin{array}{c}\text { Rp. } \\
1.894 .720 .300\end{array}$ & $12,1 \%$ \\
\hline
\end{tabular}

Sumber data : (www.kemenkeu.go.id2019)

Berdasarkan tabel diatas dapat dilihat tingkat kepatuhan wajib pajak di Indonesia yang masih rendah. Upaya yang dilakukan Dirjen Pajak untuk memaksimalkan penerimaan pajak melalui reformasi peraturan perundang-undangan di bidang perpajakan dengan menerapkan self assesment system. 
dari berbagai pilihan yang tersedia (Aryobimo, 2012).

\section{Landasan Teori}

\section{Pajak}

Definisi pajak menurut Soemitro (2014) menjelaskan bahwa pajak merupakan iuran wajib rakyat kepada kas negara berdasarkan undang-undang dengan tidak mendapat jasa timbal balik yang langsung dapat ditunjukkan dan digunakan untuk membiayai pengeluaran umum. Dari pengertian diatas disimpulkan bahwa pajak bersifat dapat memaksa dan dipungut langsung oleh pemerintah yang telah diatur dalam undang-undang.

\section{Kepatuhan Wajib Pajak}

Menurut Siti Kurnia (2017) Kepatuhan perpajakan merupakan ketaatan Wajib Pajak dalam melaksanakan ketentuan perpajakan yang berlaku

Menurut Puri (2014), kepatuhan pajak adalah suatu keadaan dimana wajib pajak memenuhi semua kewajiban perpajakan dan melaksanakan hak perpajakannya.

\section{Pemahaman Wajib Pajak}

Pengetahuan dan pemahaman peraturan perpajakan adalah proses dimana wajib pajak mengetahui tentang perpajakan dan mengaplikasikan pengetahuan itu untuk membayar pajak Resmi (2013). Menurut Fajriana (2013) mengatakan bahwa pemahaman adalah proses, cara perbuatan memahami atau memahamkan peraturan perundang-undangan perpajakan.

\section{Pelayanan Aparat Pajak}

Menurut Kusuma (2014) berpendapat bahwa pelayanan adalah suatu proses bantuan kepada orang lain dengan cara-cara tertentu yang memerlukan kepekaan dan hubungan interpersonal agar tercipta kepuasan dan keberhasilan.

\section{Sanksi Perpajakan}

Menurut Syarifudin (2016), sanksi perpajakan merupakan jaminan bahwa ketentuan peraturan perundang-undangan perpajakan (norma perpajakan) akan dituruti/ ditaati/dipatuhi atau dengan kata lain sanksi perpajakan merupakan alat (preventif) agar wajib pajak tidak melanggar norma perpajakan.

\section{Preferensi Risiko}

Preferensi risiko adalah risiko atau peluang yang dipertimbangkan oleh wajib pajak yang menjadi prioritas utama diantara yang lainnya

\subsection{Kerangka Pikir}

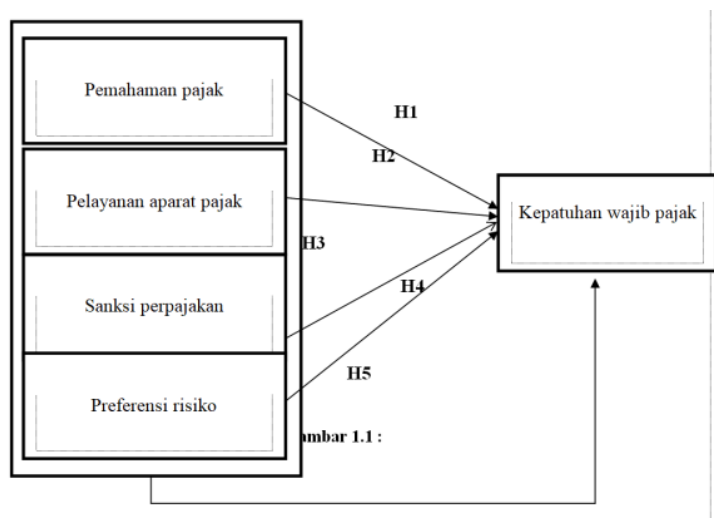

Gambar 1: Kerangka fikir

\section{MetodologiPenelitian}

\section{Desain Penelitian}

Pada penelitian ini digunakan desain penelitian kasual. Menurut Sugiono (2016:56) hubungan kasual adalah hubungan yang bersifat sebab akibat. Dalam hal ini ada variabel independen dan ada variable dependen

\section{Populasi dan Sampel}

Menurut Sugiyono (2016:115) Populasi adalah wilayah generalisasi yang terdiri atas objek subjek yang mempunyai kualitas dan krakteristik tertentu yang diterapkan oleh peneliti untuk dipelajari dan kemudian ditarik kesimpulan. Populasi dalam penelitian ini adalah 49 perusahaan manufaktur yang terdaftar di BEI periode 2013-2017 yang telah diseleksi sesuai dengan kriteria sampel yang digunakan.

Menurut Sugiyono (2017:81) sampel adalah bagian dari jumlah dan karakteristik yang dimiliki oleh populasi. Teknik pengambilan sampel (sampling) dalam penelitian ini menggunakan pertimbangan tertentu dan umumnya disesuaikan dengan tujuan atau masalah penelitian. Metode pengambilan sampel yang digunakan adalah metode cluster random sampling. Berdasarkan kriteria tersebut, peneliti mengambil sampel yang akan digunakan dalam penelitian berjumlah lebih dari 30 sampel. Jumlah ini dipilih sesuai dengan penelitian Amalia (2018) bahwa ukuran sampel yang layak 
DOI: https://doi.org/10.47233/jteksis.v1i2.46 dalam sebuah penelitian adalah $30-100$ sampel. Berdasarkan hal itu, dengan jumlah sampel minimal 30 sampel telah cukup untuk mewakili populasi dan meyakinkan peneliti untuk melakukan penelitian ini dan juga karna MetodeAnalisis

\section{Uji Regresi Linear Berganda}

Analisis regresi berganda digunakan untuk menentukan seberapa besar pengaruh variabel independen terhadap variabel dependennya. Pada penelitian ini dapat digunakan teknik regresi berganda dengan bantuan program SPSS 23. Hasil regresi linier berganda dapat dilihat pada table dibawah berikut:

Tabel 1.2

Hasil Uji Regresi Linear Berganda

\begin{tabular}{|c|c|c|c|c|c|c|}
\hline \multicolumn{7}{|c|}{10} \\
\hline \multirow[b]{2}{*}{ Model } & & \multicolumn{2}{|c|}{$\begin{array}{l}\text { Unstandardized } \\
\text { Coefficients }\end{array}$} & \multirow{2}{*}{$\begin{array}{l}\text { Standardized } \\
\text { Coefficients } \\
\text { Beta }\end{array}$} & \multirow[b]{2}{*}{$t$} & \multirow[b]{2}{*}{ Sig. } \\
\hline & & $B$ & Std. Error & & & \\
\hline 1 & (Constant) & 2,203 & 6,012 & & .366 & .717 \\
\hline & PP & ,961 & ,162 &, 785 & 5,935 &, 000 \\
\hline & PAP & , 106 & , 196 & ,058 & ,542 & ,593 \\
\hline & SP & ,029 & ,131 & ,025 & ,224 & ,825 \\
\hline & PR & ,105 & 126 &, 110 & 835 & ,411 \\
\hline
\end{tabular}

Sumber : Data Sekunder diolah dengan SPSS 23 Tahun 2019

Berdasarkan hasil analisis regresi linier berganda diperoleh persamaan garis regresinya sebagai berikut:

$\mathrm{KWP}=2,203+$ 0,961PP + 0,106PAP + 0,209SP + 0,105PR + €

1. Pengujian koefisien regresi variabel Pemahaman Perpajakan $\left(\mathrm{X}_{1}\right)$

Hasil pengujian uji t menunjukkan bahwa variabel Pemahaman Perpajakan diperoleh $t_{\text {hitung }}$ sebesar 5,935 dan $t_{\text {tabel }}$ sebesar 1,70562 yaitu $(5,935>1,70563)$, dengan tingkat signifikansi $0,000<0,05$. Maka, dapat disimpulkan Ho diterima dan $\mathbf{H}_{\mathbf{1}}$ Diterima. Artinya Pemahaman Perpajakan secara parsial berpengaruh signifikan terhadap kepatuhan wajib pajak.

2. Pengujian koefisien regresi variabel Pelayanan Aparat Pajak $\left(\mathrm{X}_{2}\right)$

Hasil pengujian uji t menunjukkan bahwa variabel gender diperoleh $t_{\text {hitung }}$ sebesar 0,542dan $t_{\text {tabel }}$ sebesar 1,70562 yaitu $(0,542<1,70562)$, dengan tingkat signifikansi 0,593>0,05 Sehingga dapat disimpulkan Ho diterima dan $\mathbf{H}_{2}$ Ditolak. Artinya Pelayanan Aparat Pajak secara parsial tidak berpengaruh signifikan terhadap kepatuhan wajib pajak.

3. Pengujian koefisien regresi variabel sanksi perpajakan $\left(\mathrm{X}_{3}\right)$ keterbatasan waktu dan lokasi penelitian yang jauh. Maka jumlah yang di ambil 30 sampel.

Hasil pengujian uji t menunjukkan bahwa variabel pemahaman pajak diperoleh $t_{\text {hitung }}$ sebesar 0,224 dan $t_{\text {tabel }}$ sebesar 1,70562 yaitu $(0,224<1,70562)$, dengan tingkat signifikansi $0,825<0,05$. Maka, dapat disimpulkan Ho ditolak dan $\mathbf{H}_{3}$ Ditolak. Artinya sanksi perpajakan secara parsial tidak berpengaruh signifikan terhadap kepatuhan wajib pajak.

4. Pengujian koefisien regresi variabel preferensi risiko perpajakan $\left(\mathrm{X}_{4}\right)$

Hasil pengujian uji t menunjukkan bahwa variabel preferensi risiko perpajakan diperoleh $t_{\text {hitung }}$ sebesar 0,835 dan $t_{\text {tabel }}$ sebesar 1,70562 yaitu $(0,835<1,70562)$, dengan tingkat signifikansi $0,411>0,05$. Maka, dapat disimpulkan Ho Ditolakdan $\mathbf{H}_{4}$ Diterima. Artinya preferensi risiko perpajakan secara parsial tidak berpengaruh signifikan terhadap kepatuhan wajib pajak.

\section{Koefisien Determinasi $\left(\mathbf{R}^{2}\right)$}

Koefisien determinasi digunakan untuk mengukur seberapa jauh kemampuan model dalam menerangkan variasi variabel dependen. Hasil uji koefisien determinasi dapat dilihat pada table dibawah ini:

Tabel 1.3

\begin{tabular}{|c|c|c|c|c|}
\hline \multicolumn{5}{|c|}{ Hasil Uji Koefisien Determinasi } \\
\hline Model & R & R Square & \begin{tabular}{|l} 
Adjusted R \\
Square
\end{tabular} & \begin{tabular}{|l} 
Std. Error \\
Estimate
\end{tabular} \\
\hline & $866^{\mathrm{a}}$ & & & 1,91 \\
\hline
\end{tabular}

Sumber: Data Primer diolah dengan SPSS 23 Tahun 2019

Dari tabel 1.3 diatas, maka dapat kita lihat pada kolom $R$-Square $=0,710$ atau 71,0\%. Hal ini berarti bahwa $71,0 \%$ kepatuhan wajib pajak dapat dijelaskan oleh variasi variabel independen yaitu pemahaman perpajakan, pelayanan aparat paja, sanksi perpajakan dan preferensi risiko perpajakan, sisanya sebesar $29,0 \%(100 \%-71,0 \%)$ dijelaskan oleh sebabsebab lain diluar model yang tidak dimasukan dalam model penelitian ini.

Pengujian Hipotesis Secara Bersama-Sama (Uji-F)

Uji $F$ ini dilakukan untuk mengetahui pengaruh semua variabel independen yang terdapat di dalam model secara bersama-sama (simultan) terhadap variabel independen. Hasil uji-f dapat dilihat pada tabel dibawah ini:

\section{Tabel 1.4}




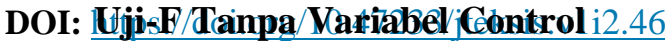

\begin{tabular}{l|r|r|r|r|r|r|}
\hline \multicolumn{2}{l|}{} & \multicolumn{1}{l|}{$\begin{array}{l}\text { Sum of } \\
\text { Squares }\end{array}$} & Df & \multicolumn{1}{l|}{$\begin{array}{l}\text { Mean } \\
\text { Square }\end{array}$} & F & Sig. \\
\hline 1 & $\begin{array}{l}\text { Regressi } \\
\text { on }\end{array}$ & 275,714 & 4 & 68,928 & 18,781 &, $000^{\circ}$ \\
& $\begin{array}{l}\text { Residual } \\
\text { Total }\end{array}$ & 91,753 & 25 & 3,670 & & \\
\hline
\end{tabular}

Sumber: Data Primer diolah dengan SPSS 23 Tahun 2019

Dari tabel 1.4 diatas uji-F menunjukan nilai $F_{\text {hitung }}$ sebesar 1,759 dan nilai $F_{\text {tabel }}$ nya sebesar 2,76dengan signifikansi sebesar 0,169>0,05. Maka, dapat disimpulkan Ho diterima dan $\mathbf{H}_{5}$ ditolak. Artinya pemahaman perpajakan, pelayanan aparat pajak, sanksi perpajakan dan preferensi risiko perpajakan berpengaruh signifikan terhadap kepatuhan wajib pajak .

\section{Kesimpulan}

Berdasarkan hasil analisis dan pengujian diatas, hasil analisis dan pengujian dalam penelitian ini, dapat disimpulkan bahwa :

1. Pemahaman Perpajakan berpengaruh positif signifikan terhadap Kepatuhan Wajib Pajak pada UMKM Elektronik di Kecamatan Sitiung Dhamasraya. Karena, pada UMKM tersebut jika memahami pemahaman pajak dan semakin tingginya jumlah pemahaman Wajib Pajak maka kepatuhan wajib pajak akan terpenuhi. Karena, mereka mengetahui penting membayar pajak untuk membangun Negara.

2. Pelayanan Aparat Pajak berpengaruh positif dan tidak signifikan terhadap Kepatuhan Wajib Pajak pada UMKM Elektronik di Kecamatan Sitiung Dharmasraya. Hal ini menunjukan bahwa pelayanan aparat pajak sangatlah penting bagi UMKM Elektronin di Kecamatan Sitiung Dhamasraya, karna dengan pelayanan aparat pajak yang baik diberikan kepada wajib pajak akan meningkatkan kepatuhan wajib pajak pada UMKM Elektronik di Kecamatan Sitiung Dhamasraya. Pada kasus ini pada UMKM Elektronik di Kecamatan Sitiung Dharmasraya pelayanan aparat pajak masih belum baik dikarenakan kurangnya ketegasan pada aparat pajak untuk meninjau UMKM tersebut.

3. Sanksi Pajak berpengaruh tidak signifikan terhadap Kepatuhan Wajib Pajak pada UMKM Elektronik di Kecamatan Sitiung Dharmasraya. Sanksi perpajakan itu sendiri pada Wajib Pajak yang ada di daerah Sitiung Dharmasraya tidaklah begitu penting walaupun Wajib Pajak tersebut paham apa pajak dan penting membayar pajak, sanksi yang diberikan tidak begitu berat dan survey pajak kurang efektif. Dan semakin tinggi sanksi yang diberikan tidak berpengaruh langsung terhadap kepatuhan seorang wajib pajak.

4. Preferensi Risiko Perpajakan berpengaruh positif dan tidak signifikan terhadap Kepatuhan Wajib Pajak pada UMKM Elektronik diKecamatan Sitiung Dharmasraya. Hal ini menunjukan bahwa seorang wajib pajak mampu menolak risiko yang tinggi adalah keadaan dimana seorang wajib akan menghadapi risiko yang berkaitan dengan kemungkinan membayar pajak atau risiko-risiko lainya.

5. Pemahaman perpajakan, pelayanan aparat pajak, sanksi perpajakan, preferensi risiko perpajakan berpengaruh positif signifikan terhadap Kepatuhan Wajib Pajak pada UMKM Elektronik di Kecamatan Sitiung Dhamasraya.

\section{Referensi}

Aziz Mohammad Ahbab Abdul, Noor Shodiq Ask, Afifudin, Pengaruh Pemahaman Peraturan Perpajakan Terhadap Kepatuhan Wajib Pajak Dengan Preferensi Risiko Sebagai Variabel Moderating (Studi Empiris Pada Wp Op Di Kpp Pratama Singosari). Vol 26-36

Djajadiningrat S.I. 2014. Perpajakan Indonesia. Jakarta : Salemba Empat Ernawati, Pengaruh Kesadaran Membayar Pajak, Pengetahuan Dan Pemahaman Peraturan Perpajakan, Persepsi Efektifitas Sistem Perpajakan Dan Pelayanan Fiskus Terhadap Kemampuan Membayar Pajak (Wajib Pajak Pribadi Pada Kpp Pratama Barabai). Vol 152-170

Hidayat, R. N., Suhadak, D., Siti, R. H., \& Bambang, W. O. (2014). Measurement model of service quality, regional tax regulations, taxpayer satisfaction level, behavior and compliance using confirmatory factor analysis. World Applied Sciences Journal,29(1), 5661.

Kartika, A. (2015). Pengaruh Pemahaman Peraturan Pajak Dan Pelayanan Aparat Pajak Terhadap Kepatuhan Wajib Pajak Dengan Preferensi Risiko Sebagai Variabel Moderasi (Studi Kasus Pada Umkm Yang Terdaftar Di Kpp Pratama Demak). 
No. 2 Juli 2019

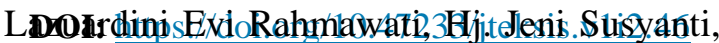
Achmad Agus Priyono, Pengaruh Pemahaman Peraturan Perpajakan, Tarif Pajak Dan Sanksi Pajak Terhadap Kepatuhan Wajib Pajak Umkm (Studi Pada Wajib Pajak Orang Pribadi Yang Terdaftar Di Kpp Pratama Malang Selatan) Vol 25-34

Listyowati, Y. C. S. (2018). Faktor-Faktor Yang Mempengaruhi Kepatuhan Wajib Pajak Dalam Membayar Pajak. Jurnal Riset Akuntansi Dan Bisnis Airlangga, 3(1).

Mardiasmo. 2018. Perpajakan Edisi Revisi Tahun 2018. Yogyakarta : Penerbit Andi

Nurhakim, T., \& Pratomo, D. (2015). Pengaruh Pemahaman Wajib Pajak Dan Kualitas Pelayanan Terhadap Kepatuhan Wajib Pajak Badan (studi Pada Kantor Pelayanan Pajak Pratama Tasikmalaya). eProceedings of Management, 2(3).

Pramesti, R. D., \& Mujiyati, D. (2018). Pengaruh Tingkat Pemahaman Wajib Pajak, Kualitas Pelayanan Fiskus, Sanksi Perpajakan, Lingkungan Wajib Pajak, Dan Penerapan E-Billing Terhadap Kepatuhan Wajib Pajak Orang Pribadi (Studi Pada Kantor Pelayanan Pajak Pratama Boyolali) (Doctoral dissertation, Universitas Muhammdiyah Surakarta).

Rahayu, Y. N., Setiawan, M., \& Troena, E. A. (2017). The role of taxpayer awareness, tax regulation and understanding in taxpayer compliance. Journal of Accounting and Taxation, 9(10), 139-146.

Resmi, Siti. 2014. Perpajakan Teori dan Kasus. Jakarta : Salemba Empat

Savitri, E. (2016). The Effect of Taxpayer Awareness, Tax Socialization, Tax Penalties, Compliance Cost at Taxpayer Compliance with Service Quality as Mediating Variable. Procedia-Social and Behavioral Sciences, 219, 682-687.

Suandy Early. Perencanaan Pajak Edisi 5 Tahun 2011. Jakarta : Penerbit Salemba Empat.

Savitri, E., \& Andreasa (2015). The Effect of Tax Socialization, Tax Knowledge, Expediency of Tax ID Number and Service Quality on
Taxpayers Compliance with Taxpayers Awareness as Mediating Variables. Procedia-social and behavioral sciences, 211, 163-169.

Tambun, S., \& Witriyanto, E. (2016). Pengaruh Kesadaran Wajib Pajak Dan Penerapan E-System Terhadap Tingkat Kepatuhan Wajib Pajak Dengan Preferensi Resiko Sebagai Variabel Moderating (Studi Empiris Kepada Wajib Pajak Di Komplek Perumahan Sunter Agung Jakarta Utara). Media Akuntansi Perpajakan, 1(2), 86-94.

Tene Johanes Herbert, Jullie J. Sondakh, Jessy D.L. Warongan, Pengaruh Pemahaman Wajib Pajak, Kesadaran Pajak, Sanksi Perpajakan Dan Pelayanan Fiskus Terhadap Kepatuhan Wajib Pajak (Studi Empiris Pada Wajib Pajak Orang Pribadi Yang Terdaftar Di Kpp Pratama Manado) Vol 443-453

Troena Afnan Eka (2016). Analisis Penerapan Peraturan Pemerintah Analisis faktor-faktor yang mempengaruhi kepatuhan wajib pajak orang pribadi (studi kasus di kpp pratama malang utara.EJurnal Akuntansi,100-121.

Wicaksono Rivan Arif, Mohamad Rafki Nazar, S.E., M.Sc, Kurnia, S.AB., M.M, Pengaruh Sanksi Perpajakan, Kualitas Pelayanan, Dan Pengetahuan Wajib Pajak Terhadap Kepatuhan Wajib Pajak(Studi Pada Wajib Pajak Orang Pribadi Non Karyawan Yang Melakukan Usaha Dan Pekerjaan Bebas Di Kpp Pratama Sumedang Tahun 2017) Vol 820-827

Wijayanti, D. W., \& Sasongko, N. (2017). Pengaruh Pemahaman, Sanksi Perpajakan, Tingkat Kepercayaan pada Pemerintah dan Hukum terhadap Kepatuhan dalam Membayar Wajib Pajak (Studi Wajib Pajak pada Masyarakat di Kalurahan Pajang Kecamatan Laweyan Surakarta).

www.kemenkeu.go.id2019 www.kompas.com WWW.Petalokasi.org(2019) 